\title{
A literatura como um destino para as ausências
}

\author{
Literature as a destination for absences \\ Laís Naufel Fayer Vaz \\ Colégio Pedro II. Rio de Janeiro, Rio de Janeiro, Brasil.
}

Resumo: A relação inversa de orfandade entre mãe e filho é desenvolvida neste conto do Padre Fábio de Melo. De forma simbólica, profunda e artesanal, o autor cria uma narrativa intimista, rica em detalhes, crítica acerca da morte, sob a ótica de quem fica, da mãe que, ao perder o filho, perde sua "função". Este artigo vista pensar a relação familiar e intimista como um dos temas da literatura contemporânea.

Palavras-chave: orfandades; Pe. Fábio de Melo; narrador; relação familiar.

\begin{abstract}
The inverse relationship of orphanhood between mother and child is developed in this story by Fábio de Melo. In a symbolic, deep and artisan way, the author creates an intimate narrative, rich in details, critical about death, from the point of view of who is left, of the mother who, losing the child, loses her "function". This article views the familiar and intimate relationship as one of the themes of contemporary literature.
\end{abstract}

Keywords: orphanhood; Fábio de Melo; storyteller; family relationships.

\author{
Perdi-me dentro de mim \\ Porque eu era labirinto, \\ E hoje, quando me sinto, \\ É com saudades de mim. \\ (SÁ-CARNEIRO, 2006, p. 10)
}

Uma das coisas que aprendi é que se deve viver apesar de. Apesar de, se deve comer. Apesar de, se deve amar. Apesar de, se deve morrer. Inclusive muitas vezes é o próprio apesar de que nos empurra para a frente.

(LISPECTOR, 1998, p. 26)

"Orfandades: o destino das ausências" é uma coletânea de contos apresentados pelos mais diversos narradores que, embora se distanciem pelas histórias que contam, encontram-se na essência de todas elas: o vazio, a perda, a solidão. "Mãe órfã", um dos textos que compõem o livro, é a história da mãe que, ao perder o filho, perde a si mesma. O que, a nosso ver, torna o texto singular é sua capacidade de provocar sensações próximas às da narradora nos leitores, contribuindo na sensibilização, na humanização dos que têm contato com a história.

Ferreira Gullar diz que fazemos arte porque a vida não basta. Para nós, "Mãe órfã" é exemplo de narrativa artesanal, arte, no estilo benjaminiano, indo além da vida real, trazendo a essência do sentimento de vazio à tona, mesmo para aqueles que nunca conheceram a sensação de perda filial ou de orfandade.

Em tom confessional, a narradora do conto "Mãe órfã" nos leva ao íntimo de sua dor, pondo o leitor diante de emoções e sentimentos que não lhe pertencem, mas que, pelo artifício da palavra, levam-no ao mundo suprassensível da arte, da leveza literária. A literatura nos alivia o peso dos dias, com sua "função existencial" (CALVINO, 1990), leve, mas precisa, preenchendo os vazios que só a arte pode satisfazer no ser humano. Em "Mãe órfã", temos a "crueza literária" (MELO, 2012, p. 5) que, pelo filtro da palavra poética, torna-se leve, porém certeira, justa no espaço narrativo. 
Há tempos, o filósofo Walter Benjamin atentara à extinção do narrador tradicional, que seria aquele que, com boas experiências a serem contadas, saberia preparar suas palavras, com temperos literários, para que seu leitor pudesse se deliciar com especial banquete. Para Benjamin, esta receita se perdeu já há algum tempo, e o que temos é um acúmulo de informações sobrepostas sem importância. $\mathrm{O}$ autor acreditava que as pessoas estavam perdendo "a faculdade de intercambiar experiências" (BENJAMIN, 1994, p. 197). Para ele, "a arte de narrar está definhando porque a sabedoria - o lado épico da verdade - está em extinção" (ibidem, p. 197).

Para nossa sorte, ainda há alguns autores que contrariam positivamente a afirmação do filósofo. Fábio de Melo é um desses autores que ainda buscam na narrativa um meio de reinventar a realidade, que parecem acreditar que a literatura “(...) torna possível vivenciar vida, e, tornando vida vivível, a literatura torna vida real" (PUCHEU, s/d, p. 2). Ainda sobrevivem, na contracorrente da modernidade, autores-artesãos, que constroem sua narrativa literária de forma a evidenciar um tipo de comunicação que

não está interessada em transmitir o 'puro em si' da coisa narrada como uma informação ou um relato. Ela mergulha a coisa na vida do narrador para em seguida retirá-la dele. Assim se imprime na narrativa a marca do narrador, como a mão do oleiro na argila do vaso (BENJAMIN, 1994, p. 199).

Sendo assim, o que afeta o leitor, numa narrativa, é menos o assunto do que o trato linguístico que a ele é dado. Ou seja, não é o que se conta, mas, sobretudo, a forma como isso é contado.

A literatura é um espaço de afetos. O filósofo Spinoza dedicou boa parte de seu livro "Ética" a pensar o que seriam "afetos", afecções que ele também chama de "paixões". O autor entende "por Paixões as afecções do corpo pelas quais o poder de agir deste corpo é acrescido ou diminuído, auxiliado ou reduzido e ao mesmo tempo as ideias dessas afecções" (SPINOZA, s/d, p. 139).

Em outras palavras, significa que a qualquer momento podemos ser abalados por alguma coisa, seja uma pessoa, um evento, um espaço, um livro. E, como consequência deste arrebatamento, podemos ter atitudes passivas, quando não produzimos nada acerca dessa afecção, ou ativas, no momento que tomamos alguma atitude. O filósofo não considera afeto como sentimento, como o define o senso-comum. Para ele, afeto é o arrebatamento que algo causa no indivíduo. O sentimento seria, portanto, uma das consequências do afeto, mas não o afeto em si.

Este artigo é, portanto, fruto de um afeto, provocado por um livro que é "filho das saudades" (MELO, 2012, p.5). Passado o deleite que o arrebatamento produz, podemos, de forma teórica, tentar explicar o que, neste conto que escolhemos, causou tal arroubo.

Optamos pelo pensamento benjaminiano no que diz respeito à sobrevivência da arte de narrar em meio à facilidade da publicação e divulgação textual que, embora garanta a quantidade, peca, muitas vezes, no que corresponde à qualidade. Além dele, convocamos Ítalo Calvino, que vê na literatura "a procura da leveza como reação ao peso da vida" (CALVINO, 1990, p.42) que dialoga, a nosso ver, com o poeta Ferreira Gullar para quem, como já dissemos, "A arte existe porque a vida não basta, a vida é pouca. E a arte nos traz coisas belas, fascinantes, atordoantes, maravilhosas. É para isso que existe." (GULLAR, 2010).

Faz-se necessária, também, a presença teórica de Gaston Bachelard que, de forma poética, pensa o devaneio, lugar em que a alma encontra um repouso. "Mãe órfã" é um conto que ilustra, também, características da literatura que o professor Godofredo de Oliveira Neto (2011) chamou "pós- pós moderna", analisando os rumos que a prosa moderna tem tomado. A literatura pós-pós traz a linguagem bem trabalhada da prosa poética, numa espécie de convite à tradição. Desenvolve-se temas como a memória, a tradição familiar, os valores humanos e a delicadeza como resposta ao excesso de violência, por exemplo. Mas não se trata de uma norma. A literatura atual é composta por todos os tipos de assuntos. É difícil teorizar, de forma didática sobre ela, pelo fato de que se escreve sobre tudo. Como vivemos tempos de liberdade (ainda que hipócrita, muitas vezes), a quantidade de assuntos possíveis de serem tratados atualmente é incalculável. Para entender, de fato, as tendências da literatura contemporânea, é preciso ler, ler muito, e pensar, sobretudo, o tempo presente e tudo o que dele faz parte.

Por fim, há ainda a questão autoral do livro, pois estamos diante de uma literatura que, por ter uma autoria sacerdotal, é, muitas vezes, equivocadamente classificada como "literatura religiosa". Quem a designa assim, certamente considera a autoria e não o conteúdo da obra. Pela leitura dos contos, percebemos que a condição sacerdotal do autor influencia sua escrita unicamente porque ambos ofícios, ser padre e ser escritor, são formas de lidar com questões humanas. Para corroborar nossos argumentos, sem dúvidas, Roland Barthes e sua teoria de "morte do autor" serão determinantes. Serão esses alguns dos teóricos que pretendemos citar na intenção de confirmar e sustentar nossos argumentos.

Passemos, então, ao conto "Mãe órfã" que, já pelo título, leva-nos a uma reflexão acerca do sintagma que o compõe. "Órfão", como sabemos, é aquele que perde os pais. Logo, uma mãe órfã, em princípio, seria uma mãe 
que perdeu seus pais. No entanto, sabemos também que, num texto literário, nada é gratuito. Sendo assim, a escolha pelo vocábulo "órfã", subordinado ao vocábulo "mãe" deve ser entendida de forma a ampliar esse significado superficial e óbvio que expusemos. Vejamos como, ao longo do texto, um novo significado poderá ser atribuído a essa expressão.

$O$ conto se inicia com uma atitude da narradorapersonagem que demonstra sua necessidade de solidão: "Cerrei a porta. Por ora quero a ilusória proteção das chaves. Um breve esquecimento do mundo é direito que julgo merecer" (MELO, 2012, p. 13). Do canto da sala, a personagem observa o triste e silencioso vazio da casa, que não deixa de ser, por analogia, a materialização de seu próprio vazio existencial. E “(...) se nos perguntarem qual o maior benefício da casa, diríamos: a casa abriga o devaneio, a casa protege o sonhador, a casa nos permite sonhar em paz" (BACHELARD, 1978, p. 201).

Só, em paz, inicia-se a divagação: "Convoco as saudades. Coloco-as sobre a mesa. (...) detalhes simbólicos do corpo que agora está privado de respiro" (MELO, 2012, p. 13). A escolha do presente do indicativo nos coloca no tempo da ação, como se nós visualizássemos e participássemos do encontro entre narradora e saudades, como se, da janela, observássemos esse momento íntimo e particular. Com as saudades sobre a mesa, iniciase a degustação indigesta do real - "Mas a realidade prevalece" (ibidem, p.13) - e, dessa forma, junto à personagem, despertamos desse pequeno devaneio. A conjunção adversativa neste período breve nos leva a crer que o despertar é malquisto, porém inevitável.

"Mãe órfã" é uma narrativa bastante simbólica, que trabalha os diversos significados de algumas imagens como o sangue, por exemplo, tecendo comparações acerca desses sentidos. Do sangue que gera vida ao sangue que se espalha na morte, o conto discorre acerca das emoções que esses dois estados desenvolvem naquele que os presencia. Por meio das metáforas, a literatura discute questões fundamentais sem fazer o alarde que textos mais denotativos poderiam provocar. E, por isso, por ser silenciosa e discreta, é que se torna uma forma de revolução potente porque trabalha com sentimentos e emoções humanas. Na medida em que tece poeticamente o sentimento da perda, o autor joga com nossa sensibilidade, aguçando-a, desenvolvendo, talvez, aquilo que mais falta no ser humano: a capacidade de empatia.

A literatura nos dá a oportunidade de nos colocarmos no lugar do outro, ou ao lado dele em suas alegrias ou sofrimentos. Muitas vezes, a sociedade nos solicita a frieza, a indiferença, e nós respondemos positivamente ao pedido, talvez, inclusive, por medo de não sermos aceitos por um grupo. Diante de um livro, na solidão que a leitura exige e proporciona, não há olhares de reprovação, não há medo e, assim, podemos encontrar o melhor de nós mesmos, nossa imensidão humana. Como defende Bachelard, "A imensidão está em nós. Está ligada a uma espécie de expansão do ser que a vida refreia, que a prudência detém, mas que retorna na solidão." (BACHELARD, 1996, p. 190). Talvez seja essa a maior contribuição da literatura, sua "utilidade" no mundo. A literatura nos devolve a sensibilidade, nossa mais importante - e quase extinta - característica humana.

É na solidão que a mãe relembra a perda do filho, numa espécie de luta pela aceitação do inaceitável. Um dos símbolos saudosos é a camisa vermelha que o filho escolhera para usar no dia de sua inesperada morte. Havia a dúvida: azul ou vermelha. Por fim, a camisa azul vencera o conflito. $\mathrm{O}$ episódio passa despercebido numa rápida leitura. Porém, como já dissemos, nada é gratuito numa narrativa. Sendo assim, por que falar sobre algo aparentemente tão irrelevante, que beira a vaidade, num conto sobre algo sério como a morte? Ao longo desse artigo, pretendemos explorar imagens e símbolos como esses, na intenção de evidenciar o caráter artesanal da narrativa, o cuidado na escolha lexical e imagética.

No vazio da sala, uma revelação: "Foi então que percebi que nós exercíamos distintas funções naquele espaço. Da casa, eu era os olhos. Ele, a voz" (MELO, 2012 , p. 15). Temos aí outra simbologia interessante. A mãe, enquanto figura responsável pela casa, é aquela que observa, denotando maturidade que, certamente, falta ao filho jovem. Ele, por sua vez, "expansivo, falante" (ibidem, p. 15) representa a jovialidade, a alegria, a graça da juventude, representando, assim, o encaixe entre duas peças perfeitas, criadas para este fim.

A narradora nos conta que a viagem do filho, esse afastamento entre eles, fora o "corte do cordão" (ibidem, p. 15), um momento em que mãe e filho deixavam de ser um só. Narra de forma poética essa cisão, mostrando que, embora dolorosa, trata-se de algo necessário. Seguido a isso, conta-nos, rapidamente, sobre o acidente em que o filho perdera a vida. É interessante notar que o fato aparece subitamente, ou seja, o foco da narrativa recai não na causa, o acidente, a morte, mas, sim, na consequência emocional dele. A notícia vem do amigo do filho: "A voz chorosa ao telefone não buscou o curativo dos rodeios. Contou-me depressa, como se ansiasse livrar-se do fardo que o sufocava. 'Leonardo morreu'. A frase era curta. O significado, não (ibidem, p. 16).

Curiosamente, o amigo que veicula a notícia se chama Gabriel. Inevitável não relacioná-lo ao anjo que anunciara o nascimento de Cristo. Porém, Gabriel, no conto, é a figura que anuncia não a vida, mas a morte. Após a notícia, 
Rolei no chão do quarto acometida pelas mesmas dores que o expulsaram do meu ventre vinte e três anos antes. As dores da morte eram as mesmas que as do nascimento. (...) $\mathrm{O}$ menino crescido não desliza no sangue da mãe, mas no seu próprio (ibidem, p. 16-17).

Por todas as imagens poéticas criadas no texto, entendemos que vida e morte têm muito em comum. A imagem do sangue é plural, na medida em que aparecerá para simbolizar o nascimento da criança e também sua morte. Além disso, a imagem da dor do parto análoga ao sofrimento pela morte também é bastante ilustrativa dessa linha tênue entre o que é vivo e o que é "privado de respiro". O choro também marca esse limite no conto: o choro do bebê ao nascer e o da mãe ao perdê-lo.

A narração acerca da preparação que Leonardo fizera para sua viagem é digna de nota devido a sua poeticidade:

Morreu entorpecido de esperança. Esperava aquela viagem como o sertanejo espera a chuva: plantando. Um detalhe por dia. Tudo especialmente preparado. Acreditava que a alegria segue a mesma regra das sementes. Germina quando é cuidada. Escolheu destino e paragens, antecipou futuro. Viu mapas, traçou rotas, quis ver o depois pelos olhos do antes (ibidem, p. 17).

Leonardo preparou-se e escolheu a camisa azul em vez da vermelha. O azul que é, muitas vezes, cor representativa da saúde e da tranquilidade, mas foi, neste caso, a cor da indumentária mortal. Porém, o azul da camisa foi coberto pelo vermelho do sangue de seu corpo no momento do acidente fatal.

O sentimento da perda é narrado de tal forma que somos levados a compartilhar da mesma emoção, sentir as mesmas dores, sermos mães por algum momento. Perder um filho é, de fato, uma terrível experiência. Porém, não é a perda em si que nos comove tanto, mas, sobretudo, a forma como a dor é narrada. Assim, sentimo-nos ao lado dessa mãe que, embora apenas personagem de um conto de ficção, parece-nos tão real.

Lembremos, então, das lições de Wolfgan Iser (1983) sobre "o que é fictício no texto ficcional". Para o autor, há elementos reais que compõem o texto fictício, como os sentimentos, por exemplo. $\mathrm{O}$ ato de fingir, no texto, propicia uma transgressão de limites que resulta no imaginário, que penetra nas nossas experiências. "Como o texto ficcional contém elementos do real, sem que se esgote na descrição deste real, então o seu componente fictício não tem o caráter de uma finalidade em si mesma, mas é, enquanto fingida, a preparação de um imaginário" (ISER. In: LIMA, 1983, p. 385). Por isso, a dor dessa mãe é real, na medida em que, inventada a partir de elementos da realidade, se instaura no imaginário do leitor, ganhando vida.
Quando o filho morre, a mãe perde sua função, pois não há mais ninguém a solicitar os cuidados maternos. Podemos, então, voltar ao título, e perceber que os papéis, embora pareçam bem delimitados, se misturam, pois mãe e filho eram um único ser. A perda do filho é também a perda da identidade. A narradora não se apresenta, não diz seu nome, sua idade, por exemplo. O amigo do filho é nomeado, Gabriel, e o filho também possui um nome: Leonardo. Mas e o nome da mãe? Já não importa. É como se "mãe" fosse seu nome, sua maior qualidade, que, agora se perdeu. E, se nada é ao acaso na narrativa, até a ausência de determinados termos ou imagens também será significativa no contexto.

"O silêncio da casa me sepulta", diz a narradora. O silêncio é aqui a ausência da voz do filho. Paradoxalmente, o silêncio é o som da angústia, o ruído da falta. Na ausência da voz, o silêncio da melancolia. "É a perda do sentido, do significado, agravado ainda mais pela lembrança que se transforma em desassossego" (MELO, 2012, p. 18). A morte silenciou o menino, a mãe, a casa, mas deu voz, sopro de vida à narrativa.

Embora tentemos, de alguma forma, "explicar" a profundidade do texto, buscando evidenciar sua beleza, sua qualidade literária, há trechos que, de tão mágicos e encantadores, dispensam nossas palavras. A seguir, um deles:

A morte de meu filho me enclausura num estado de não ser. A curva mergulhada na sombra enlaçou também a minha vida. No corpo esmagado do menino, esmaga-se também a imaterialidade que a ele me configurava como matriz. Estou meio morta, meio viva. A parte viva está com ele sepultada. Estou abrigada nos desvãos dos músculos, alojada na memória da carne que aos poucos se mineraliza. A parte morta ainda habita e caminha por esta casa (ibidem, p. 18).

Quando classificamos como belo este conto, estamos compartilhando o pensamento de Alfredo Bosi, para quem o

belo é o que arranca do tédio e do cinza contemporâneo e nos representa modos heroicos, sagrados ou ingênuos de viver e de pensar. Bela é a metáfora ardida, a palavra concreta, o ritmo forte. Belo é o que deixa entrever, pelo novo da aparência, o originário e o vital da essência (BOSI, 1977, p. 112).

O final do conto é também digno de transcrição integral:

O meu menino fora silenciado. O mesmo que sempre falava por mim, enquanto eu via o mundo por ele. O menino que Deus tomou pela mão e conduziu para ser mais uma voz no céu de muitas vozes. Por este Deus 
aqui espero. É certo que um dia Ele virá. Sua sensatez o trará até mim. Virá por caminhos que desaprendi ou que fiz questão de esquecer, não sei. Aprendi desde muito cedo que nenhuma folha se desprende da árvore sem que Ele o permita. Pois bem, se nessa fala há a prevalência da verdade, devo então entender que meu filho morto passou pelo mesmo crivo decisório. Se assim o for, eu espero que Deus venha bater à minha porta e humildemente suplique o meu perdão (MELO, 2012, p. 18).

O conto tem um final inusitado, pois tudo nos leva a crer que a mãe, por afirmar que entende os acontecimentos mundanos como vontades de Deus, atribuirá a Ele a morte do filho e, assim, amenizará seu sofrimento. Porém o eufemismo do tão difundido "foi a vontade de Deus" ou "ele está num lugar melhor" ou, ainda, "ele está bem onde estiver" não acalenta a mágoa da narradora. Seu conforto está não na esperança de uma possível vinda divina, mas na existência de uma sensatez que fará com que Deus - a figura imponente - bata à sua porta e, de forma humilde, peça-lhe perdão, numa inversão dos papéis religiosos.

Notemos que, normalmente, são os humanos que devem suplicar o perdão divino, por suas faltas, das mais simples às mais horrendas. Entretanto, os poderes se invertem e Deus, por sua sensatez, ciente de seu erro, suplica o perdão. $O$ conto acaba sem que se saiba se haverá a aceitação desse pedido - uma súplica humilde que justifique o injustificável.

Interessante notar que o conto escrito por um padre, de certa forma, questiona a fé absoluta e insensata, aquela que aceita a "vontade de Deus" como justificativa para todas as coisas e deixa de lado o raciocínio lógico, indispensável em diversas situações. Essa crítica implícita, entre outras coisas, leva-nos a crer que estamos diante de um texto que trata de questões humanas e não exclusivamente voltadas à religião. Não pretendemos aprofundarmo-nos nesta discussão, pois não a consideramos oportuna dentro desse artigo. Porém, ela serve para pensarmos acerca de preconceitos que nos impedem de viver experiências indeléveis como a leitura de um texto como esse.

Segundo Mia Couto, "o escritor não é apenas aquele que escreve. É aquele que produz pensamento, aquele que é capaz de engravidar os outros de sentimento e de encantamento" (COUTO, 2005, p. 43). Parece, então, que Fábio de Melo conseguiu cumprir, por meio de sua personagem, tal função. Analisamos um texto que é narrado por uma mulher, mãe, que perde o filho e, de forma poética e metafórica, descreve incomparavelmente tal dor. Esse texto foi escrito por um homem, o que é fator relevante, nesse caso. $\mathrm{O}$ autor conta uma experiência pela qual nunca passou nem passará de forma original e convincente como se fora uma história real contada pela mãe que a vivera. Todavia, "os poetas (no caso, consideramos o autor um poeta, na medida que escreve uma "prosa poética"), como os anjos, prescindem de gênero" afirma Karin Backes, não para negar uma condição feminina ou masculina, mas sim "para dentro de seu projeto universalizante, integrar-se ao mundo, afastando-se das diferenças" (BACKES, 2008, p. 14).

Walter Benjamin, certamente, ficaria feliz ao ler "Mãe órfã", pois veria uma narradora impregnada de sentimento e sensibilidade, expondo sua dor de forma literária e poética, numa experiência que, originando-se no particular, ganha uma dimensão universal porque fala de emoções, de humanidades. Não é relato, portanto, é arte.

A sensibilidade que encanta as palavras que constituem o texto são escolhidas, artesanalmente, por um autor que, como se sabe ou pode imaginar, é também um grande leitor. Ou seja, outros grandes escritores também o engravidaram de sentimentos com seus textos e o resultado desse afeto, no caso do autor em questão, foi a composição de novos escritos que, agora, nos engravidam de encantamentos.

Porém, ainda é preciso lembrar que, embora a biografia de um autor represente um dado importante na construção de sua obra, ela não é tão significativa quanto a obra em si nem pode servir para justificar uma análise literária. Por isso, nosso artigo propôs uma leitura do conto tendo em vista os elementos que o compõem, sem atribuir as escolhas à vida pessoal do autor.

Roland Barthes, em "O rumor da língua", afirma: "o autor entra na sua própria morte, a escrita começa". (BARTHES, 2004) Essa teoria, Barthes chamou de "morte do autor", e pode ser identificada na leitura de um texto como "Mãe órfã", em que o autor cede o espaço da narrativa para a narradora.

É interessante notar que falamos simbolicamente em algumas mortes, a do narrador e do autor. Como Benjamin afirmou, a morte do narrador inviabiliza a narrativa, pois se esse artesão não existe, o que sobra são simples e irrelevantes relatos e informações. Ao passo que a ausência de uma figura autoral, como sugere Barthes, seria um benefício ao texto, visto que os críticos não poderiam entender a narrativa por meio da vida desse autor. Seria necessário, seguindo essa lógica, portanto, tentar entender a história pela vida do narrador que a conta. Ao fazer isso, inevitavelmente, o leitor ou crítico precisaria, unicamente, de elementos intratextuais para chegar a qualquer conclusão sobre a história. Com a "morte do autor", um livro como "Orfandades" figuraria entre os clássicos da língua de língua portuguesa e seria recomendado, lido e estudado em escolas e universidades. Porém, enquanto acreditarmos que não passa de "literatura religiosa", apenas os "religiosos" irão ler. É preciso esquecer rótulos e gêneros e deixar-se levar pela fluidez 
e leveza da obra de arte, pois afetos são imprevisíveis e bons livros também.

Roland Barthes, em O prazer do texto (1987), afirma que o texto precisa dar provas de que deseja o leitor; assim, a leitura se torna uma atividade, também, erótica. Rubem Alves, comentando o texto de Barthes, diz que

o erótico é o pedacinho de pele que aparece entre o fim da manga e o princípio da luva, a nesga de carne que se mostra entre o fim da calça e o começo da blusa. Quase nada é mostrado. Tudo é sugerido. Por essa fresta estreita se abre o mundo infinito da fantasia. (...) A fantasia se mostra no não dito, no não mostrado. (...) Não foi por acidente que Mallarmé e Debussy tenham preparado o poema e a música mais cheios de neblinas e brumas para neste espaço, acontecer a dança erótica do fauno e das ninfas... (ALVES, 1990, p. 66).

Os detalhes imagéticos, as metáforas bem escolhidas, o tom confessional, a essência poética, os interstícios do texto, são algumas das provas de que ele deseja o leitor e, nós, por nossa vez, sentimo-nos atraídos por seus mistérios e encantos, pelos sentidos que aparecem entre o dito e o não dito. $\mathrm{O}$ erotismo está presente no texto que rompe com seus próprios limites, levando à transcendência autor e leitor, conduzindo-os à eternidade, "A poesia é l'éternité. C'est la mer allée avec le soleil"1. (BATAILLE, 1988, p. 22) Para Octavio Paz, "o erotismo é a potência que transfigura (...) a linguagem em ritmo e metáfora" (PAZ, 1994, p. 12).

$\mathrm{Na}$ tecedura do conto, a narradora-artesã deixou marcas desse desejo de ser lida. São marcas sutis, mas indeléveis que só leitores atentos podem perceber e saborear. Por isso, nossa análise buscou evidenciar tais marcas, de forma a propor uma leitura plausível para o conto do Pe. Fábio de Melo. Tentamos desenvolver a leitura mais completa possível, no entanto com a consciência da improbabilidade de se esgotar os sentidos de um texto literário. Por não termos tal pretensão, tão ingênua, nosso artigo é apenas uma proposta inicial de leitura que visa divulgar um texto bem escrito e de grande qualidade literária, ainda que pouco conhecido.

"Orfandades" nos revela que "a alma, mesmo quando alegrada nos rodopios intermitentes da vida, ou abraçada pelos que dela se enamoram, sabe-se misteriosamente solitária" (MELO, 2012, p.5). Sendo assim, o leitor é levado pelos subterrâneos da condição humana, ao íntimo e mais fundo dos universos particulares de personagens consistentes e quase palpáveis em sua real ficcionalidade. Não é só de ausências físicas que fala o livro, mas, também, das ausências espirituais, de um vazio existencial

\footnotetext{
1 Tradução nossa: "A poesia é a eternidade. É o mar indo com o sol."
}

que acomete o ser humano, num desconforto doloroso. Leituras são prazerosas aprendizagens, acalantos para corações solitários, sopros de vida, ainda que falem da morte.

George Steiner afirma que "onde há trabalho de mestre, onde a privacidade dos meios é instrumento de uma percepção intensificadora e não simples artifício, ao leitor se exigirá o necessário esforço" (STEINER, 1988, p.47). Sejamos leitores atentos, pesquisadores esforçados, críticos apaixonados. O leitor é sempre coautor, na medida em que precisa construir os sentidos que o texto sugere. No jogo entre o dito e não dito, o leitor caminha pelo tabuleiro do texto, com passos curtos, uma casa de casa vez, pois não importa tanto a linha de chega, mas, sim, a travessia. Nela consiste o real do humano, como já dissera Guimarães Rosa.

E, se nos perguntassem, qual seria, então, "o destino das ausências", para onde iria essa falta, esse nada tão pesado e concreto, esse espaço preenchido de vazio? Qual o destino daquilo que não suportamos, mas que nos é inato e, por isso, precisamos aprender a lidar? Há vários destinos, poderíamos responder, porém um deles, sem dúvidas, é a literatura, é a arte.

\section{Referências}

ALVES, Rubem. Tempus fugit. 5. ed. São Paulo: Paulus, 1990.

BACHELARD, G. A poética do devaneio. Tradução Antônio de P. Danesi. São Paulo: Martins Fontes, 1988.

BACHELARD, G. A poética do espaço. Tradução Antônio de P. Danesi. São Paulo: Martins Fontes, 1996.

BACKES, Karin Lilian. Mar de poeta: a metáfora do oceano nas líricas de Cecilia Meireles e Sophia Andresen. 2008. Tese (Doutorado) - Pontifícia Universidade Católica do Rio Grande do Sul, Porto Alegre, 2008.

BARTHES, Roland. A morte do autor. In: O rumor da língua. São Paulo: Martins Fontes, 2004.

BARTHES, Roland. O prazer do texto. Tradução J. Guinsburg. São Paulo: Perspectiva, 1987.

BATAILLE, Georges. O erotismo. Tradução Cláudia Fares. São Paulo: Arx, 2004.

BENJAMIN, Walter. O narrador: considerações sobre a obra de Nikolai Leskov. In: Magia e técnica, arte e politica: ensaios sobre literatura e história da cultura. São Paulo: Brasiliense, 1994.

BOSI, Alfredo. O ser e o tempo da poesia. São Paulo: Cultrix, 1977.

CALVINO, Ítalo. Seis propostas para o próximo milênio. Tradução José Barreiros. Lisboa: Teorema, 1990.

COUTO, Mia. Pensatempos. Lisboa: Caminho, 2005.

GULLAR, Ferreira. Entrevista. Revista de História, 18 ago. 2010. Disponível em: <http://www.revistadehistoria.com.br/ secao/entrevista/ferreira-gullar>. Acesso em: 23 fev. 2015. 
ISER, Wolfgang. Os atos de fingir ou o que é fictício no texto ficcional. In: LIMA, Luiz Costa. Teoria da literatura em suas fontes. Rio de Janeiro: Francisco Alves, 1983.

LISPECTOR, Clarice. Uma aprendizagem ou o livro dos prazeres. Rio de Janeiro: Rocco, 1998.

MELO, Pe. Fábio de. Orfandades: o destino das ausências. São Paulo: Planeta, 2012.

OLIVEIRA NETO, Godofredo (Org.). O pós-pós moderno: novos caminhos da prosa moderna. Rio de Janeiro: Multifoco, 2011.

PAZ, Octavio. A dupla chama: amor e erotismo. Tradução Wladir Dupont. São Paulo: Siciliano, 1994.

PUCHEU, Alberto. Poesia, para que serve? In: Pelo colorido, para além do cinzento. Rio de Janeiro: Beco do Azougue, 2007.
SÁ-CARNEIRO, Mário de. Dispersão. Rio de Janeiro: Domínio público, 2006. Disponível em: <http://www.dominiopublico. gov.br/download/texto/vo000005.pdf>.

SPINOZA, Benedictus de. Ética. Tradução Tomaz Tadeu. Belo Horizonte: Autêntica, 2009.

STEINER, George. Linguagem e silêncio: ensaios sobre a crise da palavra. Companhia das Letras: São Paulo, 1988.

Recebido: 18/07/2018

Aprovado: 03/11/2018

(D) LAÍS NAUfEL FAYER VAZ < laisnaufel@gmail.com> Professor, Colégio Pedro II, Rio de Janeiro. 